\title{
Adaptação de plano de ensino para apropriação do gênero "vídeo projeto" em aulas de língua inglesa no ensino superior
}

\author{
Rubens Fernando de Souza Lopes*
}

\begin{abstract}
Resumo
Este artigo tem como objetivo principal demonstrar como um plano de ensino de língua inglesa foi adaptado para incluir o estudo do gênero discursivo "vídeo projeto", presente em páginas virtuais de financiamento coletivo, percebido como uma necessidade a ser satisfeita por alunos de uma Faculdade de Tecnologia pública. Este é um recorte de uma Pesquisa Crítica de Colaboração que se fundamenta principalmente em Bakhtin (1952-1953/2016; 1953/1997), Newman e Holzman (1993/2002) e Vygotsky (1966/2007). Os resultados demonstram como o plano de ensino foi adaptado, observando tanto o conteúdo do material já adotado pela instituição de ensino quanto o estudo de um gênero discursivo, tendo como base o conceito de performance (dramatização).

Palavras-chave: Gênero oral. Língua inglesa. Material. Adaptação. Ensino superior.
\end{abstract}

\footnotetext{
* Instituto Federal de São Paulo (IFSP), campus Jacareí. Doutor e mestre em Linguística Aplicada e Estudos da Linguagem pela PUC-SP (2017/2009). Especialista em Língua Inglesa, licenciado em Letras e graduado em Administração. Estágio doutoral como bolsista Fulbright/CAPES na Universidade de Rutgers (the State University of New Jersey, 2015-2016). Membro do grupo ILCAE/PUC-SP (Inclusão Linguística em Cenários de Atividades Educacionais). Orcid: https://orcid.org/0000-00020941-1960.
} 


\title{
The adaptation of a course plan for the appropriation of the genre "project video" in English classes in college
}

\begin{abstract}
This article aims to demonstrate how an English language course plan was adapted to include the study of the discursive genre 'project video', which is used on online crowdfunding pages and perceived as a need to be met by students of a public College of Technology. This is part of a Critical Collaborative Research thesis which is mainly based on Bakhtin (19521953/2016, 1953/1997), Newman and Holzman (1993/2002) and Vygotsky (1966/2007). Our data demonstrate how the course plan was adapted, which included the content of the material already in use at the school and also the study of a discursive genre, and how performance (play) made it possible. Keywords: Oral genre. English language. Material. Adaptation. College.
\end{abstract}

Recebido em: 31/03/2020 // Aceito em: 30/03/2021. 


\section{Introdução}

No mundo contemporâneo, o aumento do uso de tecnologia móvel $\mathrm{e} o$ acesso facilitado à internet têm causado transformações no perfil dos alunos - estes, agora, acostumados a escolher caminhos para buscar informações que lhes interessam, desejam também ser mais participativos em seu processo de ensino-aprendizagem na escola (SERRES, 2013). Diante desse conhecimento, este artigo tem como objetivo demonstrar como, para atender necessidades de alunos do ensino superior em relação à língua inglesa, um currículo foi adaptado para incluir o ensino-aprendizagem do gênero discursivo "vídeo projeto" e, consequentemente, os elementos linguísticos que o constituem. ${ }^{1}$ Esse gênero está presente em sites especializados em "financiamento coletivo on-line" (ou on-line crowdfunding) e visa a obter capital para iniciativas de interesse coletivo por meio da agregação de diversas fontes de financiamento, geralmente pessoas físicas interessadas na iniciativa, como na produção de uma nova tecnologia, por exemplo. Para chamar a atenção de investidores, os criadores, comumente, elaboram um texto escrito assim como um vídeo descrevendo seu projeto (vídeo projeto).

A inevitabilidade de elaborar um plano específico para esse alunado surgiu de um aparente conflito de prioridades entre a faculdade e os estudantes - por um lado, a instituição prescrevia a ênfase na produção oral e uso de um material de inglês para negócios; por outro, os alunos apontavam para a necessidade de aprender inglês da área de Tecnologia e Informação e de

1 Os alunos em questão estavam matriculados no curso de Banco de Dados, do período noturno, em uma Faculdade de Tecnologia pública do Estado de São Paulo. 
desenvolver a compreensão e produção escritas. Diante desse contexto, a sugestão de um dos alunos de elaborar um vídeo projeto pareceu ser um caminho que contemplaria a necessidade de ambos os lados, pois, com a possibilidade de fazer uso de performance (dramatização) e momentos reflexivos, prevemos que os alunos poderiam trabalhar sua produção e compreensão escritas ao elaborarem seus roteiros para o vídeo, por exemplo, e sua produção e compreensão orais ao praticarem suas falas.

O que será apresentado aqui é um recorte de minha tese de doutorado (LOPES, 2017), considerada como uma Pesquisa Crítica de Colaboração (MAGALHÃES; FIDALGO, 2010). O objetivo geral da pesquisa foi analisar como alunos e professor de ensino superior tecnológico colaboram para o desenvolvimento do repertório linguístico em aulas de inglês que envolvem atividades de performance e reflexão conducentes à elaboração de um vídeo projeto de on-line crowdfunding. Ao considerar esse objetivo, podemos perceber que a elaboração do vídeo foi o objeto da atividade em que nos envolvemos em sala, e, uma vez que essa elaboração não estava prevista na ementa do curso de inglês, uma adaptação do plano de ensino, mais especificamente do conteúdo programático, precisou ser realizada. Serão essas transformações, e como foram efetuadas de forma sistematizada, que analisaremos neste artigo, pois parto do princípio de que, diante da rigidez dos currículos escolares, é possível encontrar lugar para atendermos as reais necessidades de nossos alunos. Dessa forma, assumo a autonomia defendida por Gerone-Junior (2016, p. 101), que pontua que o professor autônomo não se limita, simplesmente, a aplicar programas, mas "ele reflete sobre a realidade junto com seus alunos". 
Este trabalho está construído principalmente sobre dois pilares teóricos. Como discuto a apropriação de um gênero discursivo, procuro compreender o tema com base nas discussões de Bakhtin (1952-1953/2016; 1953/1997) e, uma vez que fiz uso de performance para possibilitar essa apropriação, busco discuti-la fundamentado em Newman e Holzman (1993/2002), Vygotsky (1966/2007) e Lobman e Lundquist (2007).

Neste artigo, além de apresentar uma discussão teórica, irei demonstrar como o plano de ensino foi organizado, tendo como base o material didático já em uso pelos alunos e a estrutura linguística do vídeo projeto, e como um planejamento baseado no conceito de performance possibilitou essa nova organização.

\section{Discussão teórica}

O objetivo desta seção é compreendermos tanto a concepção de gênero discursivo quanto a de performance, para, em seguida, tornar possível a compreensão de como ambos os conceitos podem se relacionar para compor uma proposta didática para $\mathrm{o}$ ensino de gêneros e, por conseguinte, seus elementos linguísticos constitutivos.

\subsection{Gêneros discursivos}

Bakhtin(1895-1975), ao discutir o processo de comunicação entre os seres humanos, contrapôs-se à forma como os linguistas de sua época a estudavam, isto é, com orações desconectadas de seu contexto e com ausência de negociações entre os sujeitos engajados nela. Uma das maiores contribuições deixadas pelo 
filósofo foi a noção de que nos comunicamos por meio de enunciados relativamente estáveis - gêneros - presentes nos meios pelos quais transitamos. O autor também enfatiza que cada esfera da atividade humana e da comunicação possui seus gêneros do discurso e é apenas por meio deles que falamos. Nas palavras do autor: "Em cada campo existem e são empregados gêneros que correspondem às condições específicas de dado campo.” (BAKHTIN, 1952-1953/2016, p. 18). Como esses campos de atividade humana crescem e ganham complexidade ao longo do tempo, os gêneros a eles pertencentes adquirem fluidez - estão em constante transformação.

Bakhtin (1952-1953/2016) assevera que a comunicação discursiva é complexa e aciona vários elementos ao ser realizada, incluindo tanto questões de ordem subjetiva quanto objetiva. Por isso, uma análise de orações à parte de seu contexto de produção resultaria em uma compreensão incompleta e descaracterizada do discurso. Nas próprias palavras do autor:

A vontade discursiva do falante se realiza antes de tudo na escolha de certo gênero de discurso. Essa escolha é determinada pela especificidade de um dado campo da comunicação discursiva, por considerações semântico-objetais (temáticas), pela situação concreta da comunicação discursiva, pela composição pessoal dos seus participantes, etc. Em seguida, a intenção discursiva do falante, com toda a sua individualidade e subjetividade, é aplicada e adaptada ao gênero escolhido, constitui-se e desenvolve-se em determinada forma de gênero (BAKHTIN, 1952-1953/2016, p. 3738 , grifo do autor).

Diante do exposto, podemos dizer que a comunicação é efetivada somente porque dispomos de um vasto repertório de gêneros, sejam eles orais, escritos ou híbridos. $\mathrm{Na}$ 
verdade, conforme diz o autor, os gêneros estão de tal forma tão incorporados em nossa comunicação que, apesar de não conscientes disso, nós os usamos, pois, assim como nos apropriamos de uma gramática e a dominamos mesmo antes de estudá-la na escola, isso acontece com o gênero - é um padrão linguístico flexível dado, recebido e utilizado.

Bakhtin (1952-1953/2016, p. 15), ao ampliar a discussão sobre gêneros, classifica-os em duas categorias: os primários (simples) e os secundários (complexos). Os da primeira categoria são aqueles que aprendemos em situações do dia a dia, formados nas condições da comunicação discursiva imediata. São enunciados relativamente estáveis organizados em contextos cotidianos, como conversas em lojas, restaurantes, postos de imigração no aeroporto, no táxi etc. Os pertencentes à segunda categoria são adquiridos em contextos mais formais de ensino-aprendizagem, e, como exemplo, temos o romance, o registro de pesquisas científicas, atas etc. $\mathrm{O}$ autor esclarece que esses gêneros de ordem secundária "surgem nas condições de um convívio cultural mais complexo e relativamente muito desenvolvido e organizado (predominantemente escrito) ficcional, científico, sociopolítico, etc.”, e, ainda, no processo de sua formação, eles incorporam e reelaboram os gêneros primários. (BAKHTIN, 1952-1953/2016, p. 15).

A descrição do contexto desenvolvida por Bakhtin, ao explicar como os gêneros secundários surgem, leva-nos a refletir sobre o trabalho efetuado pela escola, pois esta propõe, por meio de uma estrutura sistematizada e formal, a construção do conhecimento científico. $\mathrm{O}$ ensino de gênero no contexto escolar tem sido objeto de estudo de vários pesquisadores (LIBERALI, 2009; ANJOS-SANTOS et al., 2010; DOLZ; NOVERRAZ; 
SCHNEUWLY, 2001/2004; LOPES, 2016). Liberali (2009), por exemplo, inclui o estudo do gênero ao propor uma didática para o ensino-aprendizagem de língua estrangeira por meio do conceito de Atividade Social. Nesse enquadre, o gênero pode ser compreendido como um dos instrumentos que o sujeito utiliza para a sua efetiva participação em uma atividade. Dolz, Noverraz e Schneuwly (2001/2004), para a apropriação de um gênero, propõem o que denominam "sequência didática", composta por "apresentação da situação", "produção inicial", "módulos" e "produção final". Tanto esses autores quanto Liberali procuram abordar o ensino do gênero a partir da compreensão do contexto em que ele é produzido, conduzindo, assim, o aluno ao entendimento da relevância daquilo que está sendo abordado em sala de aula; e é com base nesse entendimento que o plano de ensino aqui apresentado foi adaptado: procurou-se, primeiramente, entender a necessidade linguística dos alunos e, uma vez revelada, foi assumida a tarefa de atendê-la de forma sistematizada.

A seguir, discutirei o conceito de performance com o fim de perceber, em seguida, como o seu uso no contexto escolar pode ser uma alternativa para adaptação de plano de ensino de língua estrangeira.

\subsection{Performance}

A performance, associada a uma das formas de brincar, tem sido alvo de pesquisas que demonstram que, ao se engajar nela, o indivíduo envolve-se em um processo de desenvolvimento de suas habilidades autorregulatórias e de linguagem (WHITEBREAD $e t$ al., 2012; NEWMAN; HOLZMAN, 1993/2002; VYGOTSKY, 1966/2007; VAN OERS; DUIJKERS, 2013). 
Vale lembrar que Vygotsky (1966/2007), precursor da discussão na qual me fundamento sobre o brincar, ao discutir a importância dessa atividade, refere-se ao jogo de papéis, ou seja, àquelas brincadeiras de "faz de conta", habitualmente criadas por crianças, como polícia e ladrão, mamãe e filhinhos e professor e aluno, as quais, por natureza, promovem a comunicação. Mesmo que o autor, ao realizar suas considerações sobre o brincar, tenha tido em mente o ser na infância, Newman e Holzman (1993/2002, p. 113) argumentam que a brincadeira pode ocorrer na fase adulta por meio do desempenho teatral (ou performance) uma atividade comum na primeira infância, mas que pode estar presente na fase adulta de maneira mais exclusiva e formalizada. ${ }^{2}$

Newman (1996, p. 144) compreende a performance como a atividade de irmos além de nós mesmos — "a estranha atividade de nos tornarmos quem não somos". (Tradução minha). ${ }^{3} \mathrm{O}$ autor acrescenta que a essência da performance é a imitação criativa coletiva, social e articulada, ou seja, é algo que seres humanos com diferentes níveis de experiência e especialidade fazem juntos, de forma a produzir algo novo a partir de qualquer material cultural à disposição. Essa imitação, como o autor enuncia, é a construção daquilo que está disponível e sua transformação completude - de forma a fazer disso algo novo.

Lobman e Lundquist (2007) contribuem para a discussão quando abordam o conceito de performance menos estruturada, denominando-a performance sem roteiro, ou improv (palavra derivada do substantivo improvisação ou improvisation, em inglês). Segundo os autores, a forma como os participantes e os elementos determinantes da prática de improviso se

\footnotetext{
$\overline{2}$ Aqui decidimos adotar esse termo (performance) devido ao significado de liberdade de criação que é atrelado a ele, fugindo ao conceito de encenações em que o performer executa somente aquilo que é dado a ele, como um roteiro pronto. (GLUSBERG, 2013; LOPES, 2018).

3 No original: "[...] performance, going beyond ourselves, the strange activity of being who we aren't."
} 
relacionam estabelece um ambiente de criatividade em que cada um pode ir além daquilo que sabe fazer, criando, dessa forma, um contexto propício para o desenvolvimento, inclusive o linguístico. Esse espaço assim se configura porque o improv determina que algumas regras sejam seguidas, como a aceitação e a apresentação de oferta, construção com base naquilo que é oferecido, prevenção de negações e apoio constante. Segundo os autores, esse ambiente estabelecido na performance de improviso assemelha-se àquele criado quando a criança está aprendendo a falar, ou seja, um espaço de suporte em que aquilo que um participante oferece é sempre aceito e torna-se material para que o outro dê continuidade à criação da cena em que estão envolvidos. Dessa forma, de acordo com os autores, uma "Zona Proximal de Desenvolvimento" é criada, definida pelos autores como

uma atividade criativa e de improviso. A ZPD é uma atividade de pessoas criando ambientes em que crianças (e adultos) podem assumir riscos, cometer erros e apoiar um ao outro no fazer aquilo que ainda não sabem como fazer. A partir dessa perspectiva, a ZPD não é uma técnica, nem mesmo uma distância, mas uma atividade, uma atividade na qual as pessoas, juntas, se engajam. (LOBMAN; LUNDQUIST, 2007, p. 6, tradução minha). 4

Lobman e Lundquist (2007) ainda propõem uma discussão pós-performance, que denominam debriefing: um momento em que os participantes se reúnem para discutir o que funcionou e o que ainda precisa ser melhorado na produção. Esse seria um encontro em que, no caso da escola, os alunos têm a oportunidade

\footnotetext{
4 No original: "[Others, we among them, see the ZPD as] a creative, improvisational activity. The ZPD is the activity of people creating environments where children (and adults) can take risks, make mistakes, and support one another to do what they do not yet know how to do. From this perspective the ZPD is not a technique, or even a distance. It is an activity, an activity that people engage in together."
} 
de refletir sobre sua performance e tomar decisões sobre como querem continuar o seu trabalho. Quando a performance é realizada em um contexto de ensino-aprendizagem de línguas, podemos assumir o debriefing como um momento em que os alunos, além de terem a possibilidade de realizar comentários gerais sobre a sua produção, podem também assinalar questões voltadas para os elementos linguísticos utilizados em suas falas.

No geral, em relação ao uso de performance em sala, corroboro a posição de Van Oers e Duijkers (2013), que compreendem o brincar como uma atividade sociocultural na qual o sujeito tem a oportunidade de vivenciar situações do dia a dia e, com isso, precisa aprender a lidar com as regras e instrumentos relacionados ao papel que assume na encenação. Incluo aqui a linguagem como um desses instrumentos. Ainda, tais autores defendem a elaboração de currículos mais flexíveis que tenham como parâmetros o conhecimento científico prescrito pela escola e que também contemplem as reais necessidades e interesses de seus alunos. Fundamentados em Vygotsky (1997), Van Oers e Duijkers (2013, p. 516) pontuam que "ensinar nesse currículo baseado no brincar torna-se (como na vida) um ato criativo no qual o professor constrói o novo dentro das restrições e provisões da situação". (Tradução minha). ${ }^{5}$ Em consonância com essa visão, assevero que o brincar traz para o currículo escolar a possibilidade de transpor para a sala de aula as práticas sociais que estão além dos muros da escola e de vivenciá-las.

A seguir, discutirei tanto a metodologia quanto a abordagem de ensino-aprendizagem que tornaram possível a adaptação do plano de ensino.

\footnotetext{
5 No original: "[...] teaching in this play-based curriculum is to become (like life) a creative act in which the teacher constructs novelty within the constraints and provisions of the situation [...]."
} 


\section{Percurso metodológico}

As alterações no plano de ensino que me propus a realizar foram possibilitadas porque tanto a metodologia de pesquisa quanto a abordagem de ensino de língua estrangeira das quais lancei mão foram adequadas para isso, pois valorizam a voz do aluno, a interação e a criatividade dos sujeitos envolvidos no processo de ensino-aprendizagem. A seguir, apresento essa metodologia, a abordagem de ensino-aprendizagem e o contexto de produção deste estudo.

\subsection{Metodologia}

Em relação à metodologia, a Pesquisa Crítica de Colaboração (PCCol) (MAGALHÃES; FIDALGO, 2010) foi adotada, pois parte da premissa de que todos os envolvidos na investigação (pesquisador e alunos) são considerados sujeitos que, juntos, constroem conhecimento e que, nesse processo, todos passam por transformações. Existe um conhecimento a ser alcançado, mas, como aponta Vygotsky (1966/2007; 1934/2008), o processo é tão importante quanto o resultado. Segundo Magalhães e Fidalgo (2010), a PCCol objetiva promover o engajamento de todos os participantes do processo e, para isso, precisamos nos afastar da concepção de que o professor ou coordenador é detentor do conhecimento referente à sua área e por isso assume o papel de transmitir o conteúdo da disciplina. Em contraposição, na perspectiva colaborativa, entende-se que todos os indivíduos no processo de ensino-aprendizagem constroem conhecimento ao participarem de forma conjunta e 
ativa. Foram essas propriedades da metodologia que permitiram que os alunos, desde o início da pesquisa, fossem convidados a participar dela, sendo questionados a respeito de seus reais interesses e contribuindo com o conteúdo com o qual gostariam de trabalhar no semestre.

\subsection{Abordagem de ensino-aprendizagem}

Durante a pesquisa, a abordagem comunicativa foi aplicada, pois esta se afasta de uma visão puramente voltada para o ensino sistêmico da língua-alvo para se aproximar de uma concepção que considera as características do contexto de produção quando um idioma é ensinado. Nessa abordagem que enfatiza a semântica, o objetivo não está somente na competência linguística, mas também na de comunicação (LARSEN-FREEMAN, 2008). Por essa razão, seus teóricos voltaram-se para o levantamento de taxonomias cujo escopo era determinar noções, funções e expoentes da língua. Para exemplificar, podemos citar a função "solicitando e oferecendo ajuda", e possíveis expoentes para isso seriam "Can you help me, please?" e "Of course!". A abordagem comunicativa procura compreender as reais necessidades dos alunos e trazer para a sala práticas pedagógicas relevantes, apresentando no material didático a língua-alvo da forma como ela é realmente utilizada nas diversas práticas sociais. Esta é uma das razões pelas quais tal abordagem, além de trabalhar com materiais autênticos em sala, faz uso da encenação. (LEFFA, 1988; LARSEN- FREEMAN, 2008). 


\subsection{Contexto}

O que estudamos neste artigo é resultado de uma pesquisa que teve início no segundo semestre de 2014, em uma Faculdade de Tecnologia do Estado de São Paulo, situada na cidade de São José dos Campos. Sua realização foi motivada, principalmente, para atender as necessidades concernentes à língua inglesa de um grupo de 21 alunos do $5^{\mathrm{O}}$ semestre, período noturno, do Curso Tecnólogo de Banco de Dados. Tendo em vista a ementa da disciplina de Inglês $\mathrm{V}$, que priorizava a oralidade, era necessário que tanto as exigências da faculdade quanto as necessidades dos alunos fossem consideradas. O plano de ensino da disciplina também previa o uso de um livro didático que estabelecia os conteúdos a serem trabalhados em sala de aula.

Assim, pôde-se observar que três elementos precisavam ser levados em conta para dar prosseguimento ao curso: (1) atender as necessidades dos alunos em relação à língua inglesa; (2) observar a prescrição da ementa de priorizar a oralidade; e (3) dar continuidade ao conteúdo do material didático já utilizado desde o primeiro semestre. O desafio imposto por esse contexto, de como esses elementos poderiam se relacionar, propulsionou o início desta investigação.

Em relação aos dois primeiros elementos, esclareço que, no início da pesquisa, questionei os alunos sobre suas verdadeiras necessidades em relação à língua estrangeira. A maioria deles demonstrou necessidade de ler e escrever. Caso isso fosse atendido, como mencionado anteriormente, haveria um possível conflito com a proposta da faculdade de desenvolver a oralidade. No entanto, uma sugestão dada por um dos alunos poderia satisfazer tanto o alunado quanto a academia: trabalhar com 
o on-line crowdfunding. Essa proposta foi aceita por todos os outros alunos porque, ao final de seu curso, para se graduarem, precisariam propor, como trabalho de conclusão, um projeto tecnológico. Isso significaria que o aluno poderia utilizar $o$ projeto de graduação como tema para criação do vídeo e, ao fazer isso, estaria se preparando para uma parte de seu trabalho final (como a elaboração de um resumo acadêmico) e também praticando a oralidade. Assim, tivemos o on-line crowdfunding como a prática social selecionada e, dentro dessa prática, que abarca vários gêneros discursivos, escolhemos produzir o gênero vídeo projeto para que a oralidade fosse praticada, mas dando espaço também para a prática da escrita e leitura.

Em relação ao terceiro elemento supracitado, e considerando a produção oral, propus um planejamento que incluiria o uso de várias atividades de performance durante o semestre, que uniriam tanto o conteúdo linguístico apontado pela análise do gênero vídeo projeto (o que veremos a seguir) quanto aquele já determinado pelo material didático.

\section{Adaptação do plano de ensino}

Uma vez que já tratamos do contexto que justifica a adaptação do plano de ensino, nesta seção, irei expor, de forma sistematizada, como isso ocorreu.

\subsection{Análise linguística do gênero vídeo projeto}

Após a definição de que iríamos trabalhar com o vídeo projeto, pautados na taxonomia da abordagem comunicativa, fiz 
um levantamento das funções comunicativas e dos elementos linguísticos necessários para elaborar esse vídeo, tendo como base a sugestão de roteiro que o site kickstarter.com oferece. ${ }^{6}$ Considerando o texto desse site, o quadro abaixo foi elaborado.

\section{Quadro 1 - Levantamento das funções comunicativas e elementos linguísticos do gênero "vídeo projeto"}

\begin{tabular}{|c|c|}
\hline Funções comunicativas & Elemento(s) linguístico(s) \\
\hline $\begin{array}{l}\text { Apresentação pessoal e de } \\
\text { outros envolvidos no projeto. }\end{array}$ & $\begin{array}{l}\text { Uso do Simple Present (nas formas } \\
\text { afirmativa, negativa e interrogativa). }\end{array}$ \\
\hline \multirow{2}{*}{$\begin{array}{l}\text { Relato da história do projeto. } \\
\text { Compartilhamento de qualquer } \\
\text { progresso que foi feito até o } \\
\text { momento, foto do protótipo } \\
\text { inicial e pesquisa já realizada. }\end{array}$} & $\begin{array}{l}\text { Uso do Simple Past (nas formas } \\
\text { afirmativa, negativa e interrogativa). }\end{array}$ \\
\hline & $\begin{array}{l}\text { Uso do Present Perfect (nas formas } \\
\text { afirmativa, negativa e interrogativa). }\end{array}$ \\
\hline \multirow{3}{*}{$\begin{array}{l}\text { Compartilhamento de uma linha } \\
\text { do tempo do planejamento de } \\
\text { como completar o projeto e } \\
\text { enviar as recompensas. }\end{array}$} & $\begin{array}{l}\text { Uso de to be + going to para falar do } \\
\text { futuro planejado. }\end{array}$ \\
\hline & $\begin{array}{l}\text { Uso de will para expressar futuro mais } \\
\text { remoto e incerto. }\end{array}$ \\
\hline & $\begin{array}{l}\text { Uso do First Conditional para fazer } \\
\text { promessas. }\end{array}$ \\
\hline $\begin{array}{l}\text { Apresentação do } \\
\text { orçamento. }\end{array}$ & Uso do Simple Present. \\
\hline
\end{tabular}

Fonte: Lopes (2017).

6 A sugestão de roteiro do site kickstarter.com, no original, é a seguinte: "Introduce yourself and any teammates involved with your project. Tell the story behind your project. Share any progress you've made so far, any photos of early prototypes, any research you've done. Potential backers appreciate these kinds of details. Share a timeline for how you plan to complete your project and send out rewards. Be open and honest about whatever you're still trying to sort out. Include your budget — even if it's just a rough one. A budget is proof that you've planned ahead. Most importantly, have fun with it! This is your chance to shine." Tradução minha: Faça a sua apresentação pessoal e daqueles envolvidos no projeto. Compartilhe seu progresso até o momento assim como fotos de protótipos e pesquisas realizadas. Potenciais investidores apreciam esses detalhes. Compartilhe uma linha do tempo sobre como você planeja concluir seu projeto e enviar recompensas. Seja aberto e honesto sobre tudo o que você ainda está tentando resolver. Inclua seu orçamento, mesmo que seja algo simples. Um orçamento é uma prova de que você se planejou antecipadamente. E o mais importante, divirta-se com isso! Esta é a sua chance de brilhar. 
Como vemos no Quadro 1, a coluna da esquerda indica as funções comunicativas necessárias para a elaboração do vídeo. $\mathrm{Na}$ coluna da direita, os elementos linguísticos correspondentes para a realização de tais funções. Para a apresentação pessoal, por exemplo, o aluno precisaria ter conhecimento de como utilizar o presente simples, nas formas afirmativa, negativa e interrogativa.

\subsection{Análise do conteúdo do livro didático}

Junto a esse levantamento, a análise do conteúdo do livro didático previsto para o semestre que os alunos estavam cursando foi realizada, como vemos no quadro a seguir. 
Adaptação de plano de ensino para apropriação do gênero "vídeo projeto" em aulas de língua inglesa no ensino superior

\section{Quadro 2 - Conteúdo de duas unidades do livro adotado na disciplina Inglês $\mathbf{V}$}

\begin{tabular}{|c|c|c|c|c|c|c|}
\hline & $\begin{array}{c}\text { Working } \\
\text { with } \\
\text { words }\end{array}$ & $\begin{array}{l}\text { Language } \\
\text { at work }\end{array}$ & $\begin{array}{c}\text { Practically } \\
\text { speaking }\end{array}$ & $\begin{array}{c}\text { Business } \\
\text { communication }\end{array}$ & $\begin{array}{l}\text { Case } \\
\text { Study }\end{array}$ & $\begin{array}{l}\text { Outcome } \\
\text { - you can }\end{array}$ \\
\hline 离 & $\begin{array}{l}\text { Air travel } \\
\text { check-in, } \\
\text { business } \\
\text { class, } \\
\text { passport } \\
\text { control, } \\
\text { etc. }\end{array}$ & $\begin{array}{l}\text { Going to } \\
\text { Infinitive } \\
\text { of purpose }\end{array}$ & $\begin{array}{l}\text { How to } \\
\text { talk about } \\
\text { money }\end{array}$ & $\begin{array}{l}\text { Travel } \\
\text { Staying in a } \\
\text { hotel }\end{array}$ & $\begin{array}{l}\text { Case } \\
\text { study } \\
\text { Organizing } \\
\text { a business } \\
\text { trip }\end{array}$ & $\begin{array}{l}\text { - Talk } \\
\text { about air } \\
\text { travel } \\
\text { - Check- } \\
\text { in at the } \\
\text { airport } \\
\text { - Talk } \\
\text { about } \\
\text { future plan } \\
\text { - Give } \\
\text { reasons for } \\
\text { actions } \\
\text { - Talk } \\
\text { about } \\
\text { money } \\
\text { - Book a } \\
\text { hotel room } \\
\text { and ask } \\
\text { about hotel } \\
\text { services }\end{array}$ \\
\hline 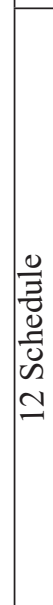 & $\begin{array}{l}\text { Calendar } \\
\text { and } \\
\text { schedules } \\
\text { busy } \\
\text { period, } \\
\text { tight } \\
\text { deadline, } \\
\text { etc. }\end{array}$ & $\begin{array}{l}\text { Present } \\
\text { Perfect }\end{array}$ & $\begin{array}{l}\text { How to use } \\
\text { prepositions } \\
\text { of time }\end{array}$ & $\begin{array}{l}\text { Meetings } \\
\text { Planning a } \\
\text { schedule }\end{array}$ & $\begin{array}{l}\text { Activity } \\
\text { The } \\
\text { revision } \\
\text { game }\end{array}$ & $\begin{array}{l}\text { - Talk } \\
\text { about } \\
\text { schedules } \\
\text { - Talk } \\
\text { about } \\
\text { recent past } \\
\text { actions } \\
\text { - Say when } \\
\text { something } \\
\text { happens } \\
\text { using } \\
\text { preposition } \\
\text { of time } \\
\text { - Say dates } \\
\text { - Plan a } \\
\text { schedule }\end{array}$ \\
\hline
\end{tabular}

Fonte: Recorte do índice do livro Business Result - Elementary -

Student's book (2009) 
O Quadro 2 mostra o conteúdo das duas unidades que precisavam ser estudadas no semestre: "Travel" e "Schedule". Além disso, expõe os aspectos gramaticais a serem abordados, o vocabulário, algumas situações para prática da oralidade, um estudo de caso e uma atividade de revisão.

\subsection{Relação dos conteúdos por meio da performance}

Após observar o conteúdo linguístico do vídeo projeto e daquele que compõe as unidades didáticas previstas para $o$ semestre, a relação entre eles foi realizada por meio de propostas de atividades que envolviam a performance.

De início, a ideia principal era apresentar o conceito de crowdfunding e solicitar, sem que houvesse muito detalhamento, que os alunos criassem um vídeo projeto que pudesse ser comparado com aquele que seria elaborado ao final do processo.

Assim, o plano era criar uma sequência de práticas em torno da performance para todo o semestre letivo. Essas práticas abordariam tanto o conteúdo do Quadro 1 quanto o do Quadro 2. Com isso, o aluno iria apropriar-se gradativamente das funções comunicativas necessárias para a reelaboração do vídeo projeto ao mesmo tempo em que teria a chance de estudar o conteúdo programático previsto pela ementa de seu curso.

Diante disso, criei dois tipos de aulas: a do Tipo 1, que previa uma sequência de atividades que apoiariam a realização de uma performance ao final da aula; e a do Tipo 2, que seria um momento em que os alunos assistiriam à sua própria performance e depois fariam o debriefing (reflexão) sobre ela, além de realizar algumas atividades escritas voltadas para o estudo gramatical. De forma mais detalhada, as aulas procuraram seguir a seguinte organização: 

a) Aula Tipo 1

1. Seleção de uma função comunicativa presente no Quadro

2. Trabalho com (a) elementos linguísticos do Quadro 1 correspondentes à função comunicativa selecionada e (b) elementos do Quadro 2 que pudessem ser vinculados à aula. $^{7}$

3. Proposta de uma performance com tema relacionado a assuntos presentes no livro didático e que evocasse o que foi abordado na aula.

b) Aula Tipo 2

1. Exibição de uma performance realizada por um grupo de alunos na aula anterior.

2. Realização de atividades voltadas ao preenchimento das lacunas observadas pelos alunos durante a exibição dessa performance e de outras que foram percebidas pelo professor durante sua análise de todas as performances.

Teoricamente, o plano de ensino proporia, primeiramente, a realização da aula Tipo 1 seguida da aula Tipo 2 e, assim, sucessivamente, considerando, logicamente, interrupções nessa sequência para a realização de atividades avaliativas, como vemos no recorte do plano de ensino, já adaptado, no quadro abaixo:

7 Essa aproximação foi realizada procurando, primeiramente, encontrar similaridades nos dois Quadros, facilitando, assim, o agrupamento adaptado de seus conteúdos. 


\begin{tabular}{|c|c|c|}
\hline DATA & CONTEÚDO PLANEJADO & $\begin{array}{l}\text { GRAVAÇÕES } \\
\text { PREVISTAS }\end{array}$ \\
\hline $13 / 08$ & $\begin{array}{l}\text { - Assunto: crowdfunding } \\
\text { Discussão: uso e importância do } \\
\text { crowdfunding } \\
\text { - Análise do site: elementos de um } \\
\text { site de crowdfunding } \\
\text { - Análise de vídeo: como fazer um } \\
\text { bom vídeo } \\
\text { - Escrevendo um roteiro + gravação } \\
\text { do primeiro vídeo }\end{array}$ & $\begin{array}{l}\text { Vídeo: } \\
\text { primeiro } \\
\text { vídeo de } \\
\text { crowdfunding }\end{array}$ \\
\hline $20 / 08$ & $\begin{array}{l}\text { - Assunto: crowdfunding - } \\
\text { apresentação pessoal e de terceiros } \\
\text { - Linguagem: expressões para } \\
\text { apresentação pessoal e das pessoas } \\
\text { ao seu redor (membros da família e } \\
\text { colegas de trabalho) e expressões de } \\
\text { check-in no aeroporto } \\
\text { - Prática: performance: Imigração de } \\
\text { aeroporto } \\
\text { - (Unidade } 11 \text { - p. } 66 \text { e 67) }\end{array}$ & $\begin{array}{l}\text { Vídeo: } \\
\text { apresentação } \\
\text { pessoal e de } \\
\text { terceiros na } \\
\text { imigração de } \\
\text { aeroporto }\end{array}$ \\
\hline $27 / 08$ & $\begin{array}{l}\text { - Assunto: crowdfunding - análise } \\
\text { - Análise de performance (reflexão) } \\
\text { - Atividades orais e escritas }\end{array}$ & $\begin{array}{l}\text { Vídeo: análise } \\
\text { (reflexão) }\end{array}$ \\
\hline 03/09 & $\begin{array}{l}\text { - Assunto: vídeo de crowdfunding - } \\
\text { compartilhando uma linha do tempo } \\
\text { - Linguagem: to be + going to para } \\
\text { falar de planos futuros; infinitivo de } \\
\text { propósito } \\
\text { - Prática: performance: minha futura } \\
\text { viagem de negócio, no táxi } \\
\text { - (Unidade } 11 \text { - p. } 69 \text { e } 70 \text { ) }\end{array}$ & $\begin{array}{l}\text { Vídeo: minha } \\
\text { futura viagem } \\
\text { de negócio }\end{array}$ \\
\hline $10 / 09$ & $\begin{array}{l}\text { - Assunto: crowdfunding } \\
\text { - Análise de performance (reflexão) } \\
\text { - Atividades escritas e orais }\end{array}$ & $\begin{array}{l}\text { Vídeo: análise } \\
\text { (reflexão) }\end{array}$ \\
\hline
\end{tabular}


Adaptação de plano de ensino para apropriação do gênero "vídeo projeto" em aulas de língua inglesa no ensino superior

\begin{tabular}{|c|c|c|}
\hline $17 / 09$ & $\begin{array}{l}\text { - Assunto: crowdfunding - a história } \\
\text { por detrás do meu projeto } \\
\text { - Linguagem: revisão de Simple Past } \\
\text { - Prática: performance: minha última } \\
\text { viagem de negócios }\end{array}$ & $\begin{array}{l}\text { Vídeo: minha } \\
\text { última viagem } \\
\text { de negócios }\end{array}$ \\
\hline $24 / 09$ & $\begin{array}{l}\text { - Assunto: crowdfunding } \\
\text { - Análise de performance (reflexão) } \\
\text { - Atividades escritas e orais }\end{array}$ & $\begin{array}{l}\text { Vídeo: análise } \\
\text { (reflexão) }\end{array}$ \\
\hline $1 \% / 10$ & $\begin{array}{l}\text { - Prática oral: performance } \\
\text { - Avaliação oral } 1\end{array}$ & $\begin{array}{l}\text { Vídeo: } \\
\text { apresentação } \\
\text { de uma das } \\
\text { situações }\end{array}$ \\
\hline
\end{tabular}

Fonte: Lopes (2017).

Diante do quadro acima e a exemplo do que foi explicado, percebemos que, no dia 20/08, os alunos, para praticar a função "apresentação pessoal e de terceiros" assim como o uso do Simple Present, teriam que criar uma performance na "imigração do aeroporto". A escolha do contexto "aeroporto" se justificou pelo fato de que este possibilitaria o uso de palavras, expressões e expoentes utilizados nesse espaço (exigência do material em uso - páginas 66 e 67) e apresentação pessoal (uma das necessidades percebidas no vídeo projeto). No dia 27/08, uma semana depois, os alunos teriam a oportunidade de fazer o debriefing de suas performances que foram gravadas.

Já para o dia 03/09, o plano foi trabalhar com a função "compartilhando uma linha do tempo", usando o to be + going to para falar sobre ações futuras planejadas: uma necessidade do vídeo projeto e um conteúdo previsto no material didático. A proposta de performance desse dia foi realizada tendo como base o tema da Unidade 11: Travel. 
Durante o semestre letivo, logicamente, algumas alterações no plano de ensino foram realizadas, mas, no total, seis gravações foram feitas. Para isso, duas configurações de atividades performáticas foram estipuladas: uma que denominei "ensaio de performance" e outra, de "performance de improviso". $\mathrm{Na}$ primeira configuração, os alunos recebem uma situação comunicativa $^{8}$ em que precisam atuar utilizando os elementos linguísticos trabalhados em aula. Nesse momento em que não há plateia, mas apenas outros colegas de aula também realizando suas cenas, os participantes da performance podem fazê-la e refazê-la quantas vezes julgarem necessário. Fazem a gravação final em áudio pelo smartphone e a enviam ao professor em seguida. A intervenção entre os participantes é livre assim como a consulta a materiais didáticos, internet, outros colegas e ao professor. Na performance de improviso, é proposta uma situação comunicativa que evoca elementos linguísticos semelhantes aos do ensaio; porém, os alunos, em seus grupos ou duplas, atuam em uma sala separada somente diante de uma câmera. Apenas o professor é a plateia. Nesse momento, precisam atuar de acordo com as regras do teatro de improvisação, sem interromper a cena para fazer consultas. A performance é gravada e armazenada para análise. Das seis gravações, a última foi a do vídeo projeto, que evocou dos alunos as habilidades linguísticas que foram gradativamente desenvolvidas durante o semestre.

No resultado da pesquisa realizada (LOPES, 2017), verificamos que, na adaptação do currículo com atividades de performance e reflexão, alunos e professor estabelecem colaboração e tornam-se sujeitos ativos em seu processo de ensino-aprendizagem, fazendo uso de ações discursivas que

8 As situações comunicativas foram denominadas: Fronteira israelense, Imigração de aeroporto, Conversa sobre viagem a negócios, Conversa sobre viagem para congresso, Discutindo o trabalho de conclusão de curso e Vídeo projeto de crowdfunding. 
promovem o desenvolvimento de seu repertório linguístico, com recursos em língua inglesa que vão além daqueles necessários para a produção do vídeo projeto.

\section{Considerações finais}

Diante do exposto, podemos perceber que a demanda da faculdade foi atendida na medida em que o plano de ensino contemplou a criação de performance, que, em sua essência, exige que os alunos pratiquem tanto sua produção quanto compreensão orais. Além disso, o conteúdo previsto no livro didático voltado para inglês de negócios pôde ser, de alguma forma, contemplado, uma vez que o plano de ensino procurou associá-lo ao trabalho com funções comunicativas e elementos linguísticos que precisavam ser aprendidos para a elaboração do vídeo projeto. Já em relação à necessidade dos alunos de trabalhar o inglês da área de TI, podemos dizer que foi atendida ao considerarmos que seus vídeos abordavam justamente o projeto tecnológico que precisariam apresentar para a conclusão de seu curso na instituição. Além disso, concernente ao desejo expresso de praticarem a produção e compreensão escritas, os alunos, em vários momentos, precisaram fazer leituras de textos no livro didático, escrever seus roteiros e realizar atividades gramaticais diante das lacunas notadas em suas performances.

Podemos notar que a adaptação não se deu de forma simples, pois vários são os elementos que compõem esse contexto: os temas do material já em uso, seu conteúdo programático, os objetivos da ementa e a necessidade dos alunos. Esses elementos, a princípio, por configurarem um conflito, poderiam ser compreendidos como entrave em um processo de ensino- 
aprendizagem. No entanto, a discussão realizada acima visou a demonstrar que, mesmo diante de conflitos, é possível realizar adaptações para que o currículo escolar se torne relevante para o aluno, sem pretender, logicamente, defender que a adaptação aqui exposta seja a única maneira de atender a demandas levantadas por alunos e sua instituição de ensino. Em nosso caso, evidenciamos que a performance foi um instrumento de elevada importância para relacionar conteúdos de matrizes diferentes, promovendo assim um trabalho para a apropriação de um gênero discursivo: o vídeo projeto.

\section{Referências}

ANJOS-SANTOS, Lucas M. et al. Uma proposta de planejamento de ensino de língua inglesa em torno de gêneros textuais. Letras, Santa Maria, v. 20, n. 40, p. 191-215, jan./jun. 2010.

BAKHTIN, Mikhail M. (1953). Estética da criação verbal. São Paulo: Martins Fontes, 1997.

BAKHTIN, Mikhail M. (1952-1953). Os gêneros do discurso. Tradução Paulo Bezerra. São Paulo: Editora 34, 2016.

DOLZ, J.; NOVERRAZ, M.; SCHNEUWLY, B. (2001) Sequências didáticas para o oral e a escrita: apresentação de um procedimento. In: DOLZ, J.; SCHNEUWLY, B. Gêneros orais e escritos na escola. Mercado de Letras: Campinas. 2004. p. 95-128.

GERONE-JUNIOR, A. Desafios ao educador contemporâneo: perspectivas de Paulo Freire sobre a ação pedagógica de professores. Curitiba: Intersaberes, 2016.

GLUSBERG, J. A arte da performance. Trad. Renato Cohen. São Paulo: Perspectiva, 2013. 
Adaptação de plano de ensino para apropriação do gênero "vídeo projeto" em aulas de língua inglesa no ensino superior

GRANT, David; Hughes, John; Turner, Rebecca. Business Result. Elementary. Student's book. Oxford: OUP, 2009.

LARSEN-FREEMAN, Diane. Techniques and principles in language teaching. 2nd. China: Oxford University Press, 2008.

LEFFA, Vilson J. Metodologia do ensino de línguas. In: BOHN, Hilário I.; VANDRESEN, Paulino. Tópicos em linguística aplicada: o ensino de línguas estrangeiras. Florianópolis, SC: Ed. da UFSC, 1988. p. 211-236.

LIBERALI, Fernanda C. Atividade social nas aulas de língua estrangeira. São Paulo: Moderna, 2009.

LOBMAN, Carrie; LUNDQUIST, Matthew. Unscripted learning: using improv activities across the K-8 curriculum. New York: TC Press, 2007.

LOPES, Rubens F. S. A agência relacional em aulas de inglês baseadas em performance. In: CHAO, Vicente López; GONZÁLEZ, Pilar Sánchez; NICOLÁS, Ana Botella. (org.). Contenidos Universitarios Innovadores, Barcelona, v. 1, p. 31-46, 2018.

LOPES, Rubens F. S. A colaboração para o desenvolvimento do repertório linguístico em atividades de performance teatral e reflexão em aulas de inglês no ensino superior tecnológico. 2017. Tese (Doutorado em Linguística Aplicada e Estudos da Linguagem) - LAEL, Pontifícia Universidade Católica, São Paulo, 2017.

LOPES, Rubens F. S. Material didático de língua inglesa: uma possível ferramenta para a inclusão de alunos em situação de risco no processo de ensino-aprendizagem. The ESPecialist, [ $s$. l.], v. 37, p. 87-111, 2016.

MAGALHÃES, Maria Cecília C.; FIDALGO, Sueli S. Critical collaborative research: focus on the meaning of collaboration and on mediational tools. RBLA, Belo Horizonte, v. 10, n. 3, p. 773-797, 2010. 
NEWMAN, Fred. Performance of a lifetime: a practicalphilosophical guide to the joyous life. New York: Castillo International, Inc., 1996.

NEWMAN, Fred; HOLZMAN, Louis. (1993). Lev Vygotsky: cientista revolucionário. Tradução de Marcos Bagno. São Paulo: Edições Loyola, 2002.

SERRES, Michel. Polegarzinha. Tradução Jorge Bastos. Rio de Janeiro: Bertrand Brasil, 2013.

VAN OERS, Bert; DUIJKERS, Debbie. Teaching in a play-based curriculum: theory, practice and evidence of developmental education for young children. Journal of Curriculum Studies, [s. l.], v. 45, n. 4, p. 511-534, 2013.

VYGOTSKY, Lev S. Educational psychology. Boca Raton, FL: St Lucie Press, 1997.

VYGOTSKY, Lev S. (1966). O papel do brinquedo no desenvolvimento. In: COLE, M. et al. Formação social da mente: o desenvolvimento dos processos psicológicos superiores. São Paulo: Martins Fontes, 2007. p. 107-124.

VYGOTSKY, Lev S. (1934) Pensamento e Linguagem. São Paulo: Martins Fontes, 2008.

WHITEBREAD, David et al. The importance of play. A report on the value of children's play with a series of policy recommendations. University of Cambridge, 2012. 